\title{
Prevalence of Glucose-6-Phosphate Dehydrogenase (G6PD) Deficiency among Malaria Patients in Southern Thailand: 8 Years Retrospective Study
}

\author{
Thunchanok Khammanee ${ }^{1}$, Nongyao Sawangjaroen ${ }^{1}$, Hansuk Buncherd ${ }^{2}$, Aung Win Tun ${ }^{3}$, \\ Supinya Thanapongpichat ${ }^{2, *}$ (i) \\ 'Division of Biological Science, Faculty of Science, Prince of Songkla University, Hat Yai, Songkhla 90110, Thailand; ${ }^{2}$ Faculty of Medical Technology, \\ Prince of Songkla University, Hat Yai, Songkhla 90110, Thailand; ' Faculty of Graduate Studies, Mahidol University, Salaya, Nakhon Pathom 73170 , \\ Thailand
}

\begin{abstract}
Erythrocytes deficient in glucose-6-phosphate dehydrogenase (G6PD) is more susceptible to oxidative damage from free radical derived compounds. The hemolysis triggered by oxidative agents such as primaquine ( $P Q$ ) is used for the radical treatment of hypnozoites of $P$. vivax. Testing of G6PD screening before malaria treatment is not a common practice in Thailand, which poses patients at risk of hemolysis. This retrospective study aimed to investigate the prevalence of G6PD in malaria patients who live in Southern Thailand. Eight hundred eighty-one malaria patients were collected for 8-year from 2012 to 2019, including 785 (89.1\%) of $P$. vivax, 61 (6.9\%) of $P$. falciparum, 27 (3.1\%) of $P$. knowlesi, and 8 $(0.9 \%)$ of mixed infections. The DiaPlexC genotyping kit (Asian type) and PCR-RFLP were employed to determine the G6PD variants. The result showed that 5 different types of G6PD variants were identified in 26 cases (2.9\%); $12 / 26$ $(46.2 \%)$ had Mahidol (487G $>A)$ and 11/26 (42.3\%) had Viangchan (871G $>A$ ) variants, while the rest had Kaiping $(1388 G>A)$, Union $(1360 C>T)$, and Mediterranean $(563 C>T)$ variants. G6PD Songklanagarind $(196 T>A)$ variant was not found in the study. Our result did not show a significant difference in the malaria parasite densities in patients between G6PD-deficient and G6PD-normal groups. According to our findings, testing G6PD deficiency and monitoring the potential $P Q$ toxicity in patients who receive $P Q$ are highly recommended.
\end{abstract}

Key words: G6PD, malaria, P. vivax, Southern Thailand

\section{INTRODUCTION}

G6PD deficiency is the most common X-linked recessive hereditary enzymopathy in humans, which affects over 500 million people globally [1]. G6PD plays a crucial role in the first step of the pentose phosphate pathway (PPP), which is the only source of generating the co-enzyme, nicotinamide adenine dinucleotide phosphate (NADPH), in RBCs. The NADPH passes the electron to oxidized glutathione (GSSG) in the antioxidant pathway, producing the reduced glutathione (GSH). The GSH generation helps to protect cells from oxidative stress by removing the reactive oxygen species (ROS) [2]. G6PD activity is therefore crucial for protecting cells against oxidative

- Received 27 August 2021, revised 5 December 2021, accepted 22 December 2021. *Corresponding author (supinya.th@psu.ac.th) (c) 2022. Korean Society for Parasitology and Tropical Medicine This is an Open Access article distributed under the terms of the Creative Commons Attribution Non-Commercial License (https://creativecommons.org/licenses/by-nc/4.0) which permits unrestricted non-commercial use, distribution, and reproduction in any medium, provided the original work is properly cited. damage. The gene encoding G6PD is highly polymorphic. Its mutations frequently cause clinical manifestation because of decreased enzyme activity and stability [3]. Most G6PD deficiency patients show no symptoms until exposure to external triggers that could lead to moderate and severe symptoms, such as acute or chronic hemolytic anemia, favism, neonatal jaundice, and hyperbilirubinemia [4]. The hereditary G6PD enzyme deficiency distributes in males and varies among ethnic groups in different geographic regions, ranging from $0 \%$ in the native American to $20 \%$ or more in African and Asian $[1,5]$. Notably, the distribution of G6PD deficiency correlates with the malaria-endemic areas [6], showing the evolutionary selection of G6PD deficiency by malaria. The impairment of G6PD conferred the inhibition of in vitro parasite growth [7] and the protection against complicated malaria because of the early phagocytosis of infected RBC [8].

Previous clinical studies showed that G6PD A-variant in Africa protects against severe falciparum malaria disease only in hemizygous males [9] or heterozygous female children [10]. 
Although G6PD deficiency provides an advantage under natural selection by malaria, the patient with G6PD deficiency who received an anti-malarial drug, e.g., primaquine (PQ), may suffer hemolytic anemia [11]. The PQ prevents the relapse of $P$. vivax and $P$. ovale by killing the hypnozoite in liver cells and blocking the gametocyte of $P$. falciparum $[12,13]$. The severity of hemolysis depends on G6PD variants. Although the G6PD deficiency is rare, its prevalence in the regions where malaria is common would be over $10 \%$ [14]. Howes RE et al. [6] reported approximately $13-17 \%$ of Thai population carries common G6PD variants. This global prevalence of G6PD deficiency was estimated using a Bayesian geostatistical model which predicted the allele frequency of the G6PD deficiency map across endemic malaria countries. Among the Thai population, G6PD Mahidol, Viangchan, Canton, Kaiping, Mediterranean, Songklanagarind, Union, Vanua Lava, Chinese-5, Gaohe, KeralaKalyan and Quing Yan were observed. The G6PD variants are diverse among ethnicities and geographical regions. The Mahidol and Viangchan variants were the most common among Thais and people of other races. In the Thai population, G6PD Mahidol was as high as $94.92 \%$ of Thais living near the ThaiMyanmar border [15] while it was $20 \%$ in the north [16]. In contrast, Viangchan variant was dominant in southern Thailand with 46.8\% found in Surat Thani province [17], 24.14\% in Phuket province [18], and 31.3\% in Songkhla province [19]. Among ethnic groups, G6PD Mahidol variant was detected in more than 90\% of Karen and Myanmar people in the northwest [20], and 13.1\% of Myanmar [17], and 37.9\% of Moken people in the south [18]. In the Northeast, $31 \%$ of the Loa ethnicity carried the G6PD Viangchan variation [21]. In addition, Chinese G6PD mutations were found significant numbers in the northern region. Kaiping G6PD variant was found in 5.4\% and $18 \%$, and the Canton variant was $6.42 \%$ and $16 \%$ were presented in the Lue and Thai ethnic groups, respectively [16, 22].

However, G6PD deficiency testing in malaria patient is required before PQ administration, but the procedure is poorly implemented [11]. Information about the distribution of the G6PD variants would be necessary for the implication of primaquine policy. Even though several studies have reported the prevalence of G6PD deficiency in malaria patients from elsewhere in Thailand $[23,24]$. There is a limited data available for the southern Thailand, where malaria is still a problem and potential to increase. There has been no assessment of the G6PD deficiency frequencies in malaria-infected patients who resided or worked in malaria-endemic areas of southern Thailand. Therefore, the present study aims to investigate the prevalence of G6PD variants in malaria patients from southern Thailand.

\section{MATERIALS AND METHODS}

\section{Ethical statement}

This study was approved by the Ethical Review Committee for Research in Human Subjects, Prince of Songkla University (HSc-HREC-63-6-1-1).

\section{Study area and subjects}

This retrospective study was performed using dried blood spots samples from the previous study conducted in the southern Thailand [25-27], during 2012-2019. A total of 881 dried blood spots samples were diagnosed with malaria infection by the microscopic method from the malaria clinics at the Office of Disease Prevention and Control 11 and 12, Thailand. All finger-prick dried blood spot samples were collected on Whatman No.3 filter paper (GE Healthcare, Buckinghamshire, UK). These samples had been registered at malaria clinics from 5 sites in the Southern regions of Thailand: Ranong, Chumphon, Phang-nga, Surat Thani (located in the upper part of the south), and Yala (the southernmost province).

At the malaria clinic, microscopic examination of thick and thin smears was performed to detect infection, to estimate parasitemia and identify the parasite stage. The malaria parasites were counted against 200 white blood cells of thick film and 1,000 red blood cells of the thin film. Then, the parasite density (parasites/ $/$ l) was calculated from the number of parasites counted per $200 \mathrm{WBCs} \times 8,000 \mathrm{cells} / \mu \mathrm{l}$ (assumed WBC count in patients) of thick film and parasitized cells $\times$ an estimated $5,000,000$ average red cells divided by 20 fields $\times 250$ RBCs for thin blood smear [28]. The parasitic density was a geometric mean of 4,236 parasites/ $\mu \mathrm{l}$ (95\% CI, 8-47,607 parasites/ $\mu \mathrm{l}$ (as-

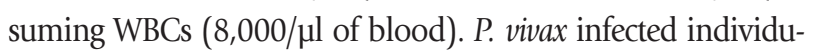
als were treated with $25 \mathrm{mg} / \mathrm{kg}$ chloroquine and $0.25 \mathrm{mg} / \mathrm{kg}$ primaquine for 14 days as the first-line drugs according to the Ministry of Public Health, Thailand.

\section{Plasmodium detection and G6PD variants analysis}

Genomic DNA was extracted using QIAamp DNA Blood Mini Kit (Qiagen, Hilden, Germany) according to the manufacturer's recommendation for dried blood spots. DNA was 
eluted in $100 \mu \mathrm{l}$ of the elution buffer and used as templates for molecular approach. Plasmodium parasites species $P$. falciparum, P.vivax, P. ovale, and P. malariae were confirmed by nested PCR assay based on the $18 \mathrm{~S}$ ribosomal RNA (18S rRNA) gene as described previously [29]. P. knowlesi species was confirmed with the cytochrome $b$ (Cyt $b$ ) gene by nested PCR assay [30]. G6PD genotyping variants were identified using DiaPlexC ${ }^{\mathrm{TM}}$ G6PD Genotyping Kit (Asian type; SolGent, Korea) with onestep PCR. The different amplicon sizes from the 8 G6PD variants were produced as follow: Vanua Lava (383T $>$ C, $154 \mathrm{bp}$ ), Mediterranean (563C > T, 262 bp), Coimbra (592C > T, 234 bp), Mahidol (4,87G >A, 337 bp), Viangchan (871 G>A, 501 bp), Kaiping (1,388G $>A, 557$ bp), Canton (1,376G $>$ T, 681 bp) and Union (1,360C $>$ T, 803 bp). Amplification was performed with an initial denaturation at $95^{\circ} \mathrm{C}$ for $15 \mathrm{~min} ; 30 \mathrm{cy}$ cles of $95^{\circ} \mathrm{C}$ for $30 \mathrm{sec}, 60^{\circ} \mathrm{C}$ for $30 \mathrm{sec}$, and $72^{\circ} \mathrm{C}$ for $40 \mathrm{sec}$; and a final extension at $72^{\circ} \mathrm{C}$ for $5 \mathrm{~min}$. PCR reactions were conducted in a $25 \mu \mathrm{l}$ reaction mixture containing $5 \mu \mathrm{l}$ of template, $12.5 \mu \mathrm{l}$ of $2 \mathrm{X}$ multiplex PCR smart mix (G6PD Asian type), $2 \mu$ of primer mixer (G6PD Asian type), $5.5 \mu \mathrm{l}$ of nuclease-free water. The PCR products were resolved on 3\% agarose gels electrophoresis at $100 \mathrm{~V}$ in the Tris-Borate-EDTA buffer and then visualized by UV light after staining with ethidium bromide. The internal control was confirmed at band 1,234 bp. G6PD Songklanagarind, the nucleotide changed from the TTC > ATC at codon 196 in the exon 4 of the G6PD gene, was detected by polymerase chain reaction-restriction fragment length polymorphism (PCR-RFLP). A pair of primers and PCR conditions were used as previously described [19]. According to the manufacturer's instruction, the PCR products were digested with $10 \mathrm{U}$ of FastDigest BstXI (Thermo Fisher Scientific, Waltham, Massachusetts, USA).

\section{Data analysis}

Malaria parasite density was determined in the G6PD deficient and non-deficient groups using the student's t-test. The parasite count on a thick film was examined, consisting of 686/785 of $P$. vivax and 48/57 of $P$. falciparum and 8 samples were mixed infections between $P$. vivax and $P$. falciparum.

\section{RESULTS}

\section{Prevalence of G6PD mutation variants}

The study was conducted in Ranong $(n=178)$, Chumphon $(n=75)$, Phang-nga $(n=7)$, Surat Thani $(n=59)$ and Yala $(n=$
562). Among 881 malaria patients, 298 (33.9\%) were females, and 506 (57.4\%) were males, while no data was available for the rest $77(8.7 \%)$. The majority of the patients were Thai (779; 88.4\%), followed by Myanmar (99; 11.3\%) and Laos (3; $0.4 \%$ ), respectively (Fig. 1 and Table 1). P. vivax was detected in $785(89.1 \%)$, P. falciparum in $61(6.9 \%), P$. knowlesi in 21 (3.1\%), and mixed infection in $8(0.9 \%)$ (P. vivax and $P$. falciparum) of the patients. The G6PD variants were detected in 26 out of 881 patients (2.9\%) and the rest 855 patients were normal G6PD individuals (97.1\%). The prevalence of 26 G6PDdeficient persons varied by the locations represented in Table 1 . In order of prevalence from highest to lowest, they were $28.6 \%$ (2/7) in Phang-nga, 7.4\% (13/178) in Ranong, 5.4\% (4/75) in Phumphon 1.8\% (1/59) in Surat Thani and 1.1\% (6/562) from 1.1\% (6/562) in Yala. These 26 samples had 5 different G6PD variants: Mahidol variant comprised 46.2\% (12/26); Viangchan variant $42.3 \%$ (11/26), and a single case each of Kaiping, Union, and Mediterranean (3.85\% of each). There was no Songklanagarind variant observed in this study. Among the G6PD deficiency individuals, 73.1\% (19/26) were Thais, 23.1\% (6/26) Burmese and 3.8\% (1/26) Laos, while 13/26 (50\%) were males and $8 / 26$ (38.5\%) females (Table 1). Only the samples infected with P. falciparum and P. vivax had G6PD variants, while $P$. knowlesi-infected blood samples possessed normal G6PD. As illustrated in Fig. 1, the prevalence and type of G6PD-deficiency varied among the regions: from 1.1\% (6/562) in Yala to 7.3\% (13/178) in Ranong. Ranong province at the Thai-Myanmar border showed a high frequency of the persons carrying G6PD variants, both in Thai and Burmese individuals with $53.8 \%(7 / 13)$ and $46.1 \%(6 / 13)$ respectively (Table 1). Among the Burmese ethnic group, 66.6\% (4/6) of G6PD Mahidol and 33.4\% (2/6) of G6PD Kaiping and Union, were observed respectively. G6PD mutations with a rate of $5.3 \%$ (4/75) were identified as Mahidol and Viangchan variants from Chumphon. Of these, 25\% (1/4) was Mahidol variant observed in Lao, and the rest $75 \%$ (3/4) were Thais with $66.7 \%$ (2/3) of Mahidol and 33.3\% (1/3) of Viangchan variants, respectively. One Thai patient with Mahidol variant, accounting for $1.7 \%$ (1/59), was found in Surat Thani. G871A mutation of G6PD Viangchan was observed in 2 out of 7 (28.6\%) Thai patients from Phang-nga. In Yala province, 6 out of 562 samples (1.1\%) were found to contain G6PD mutations, of which $66.7 \%$ (4/6) and 33.3\% (2/6) were Mahidol and Viangchan variants, respectively. As described above, G6PD deficiency was relatively higher in the upper south provinces than 


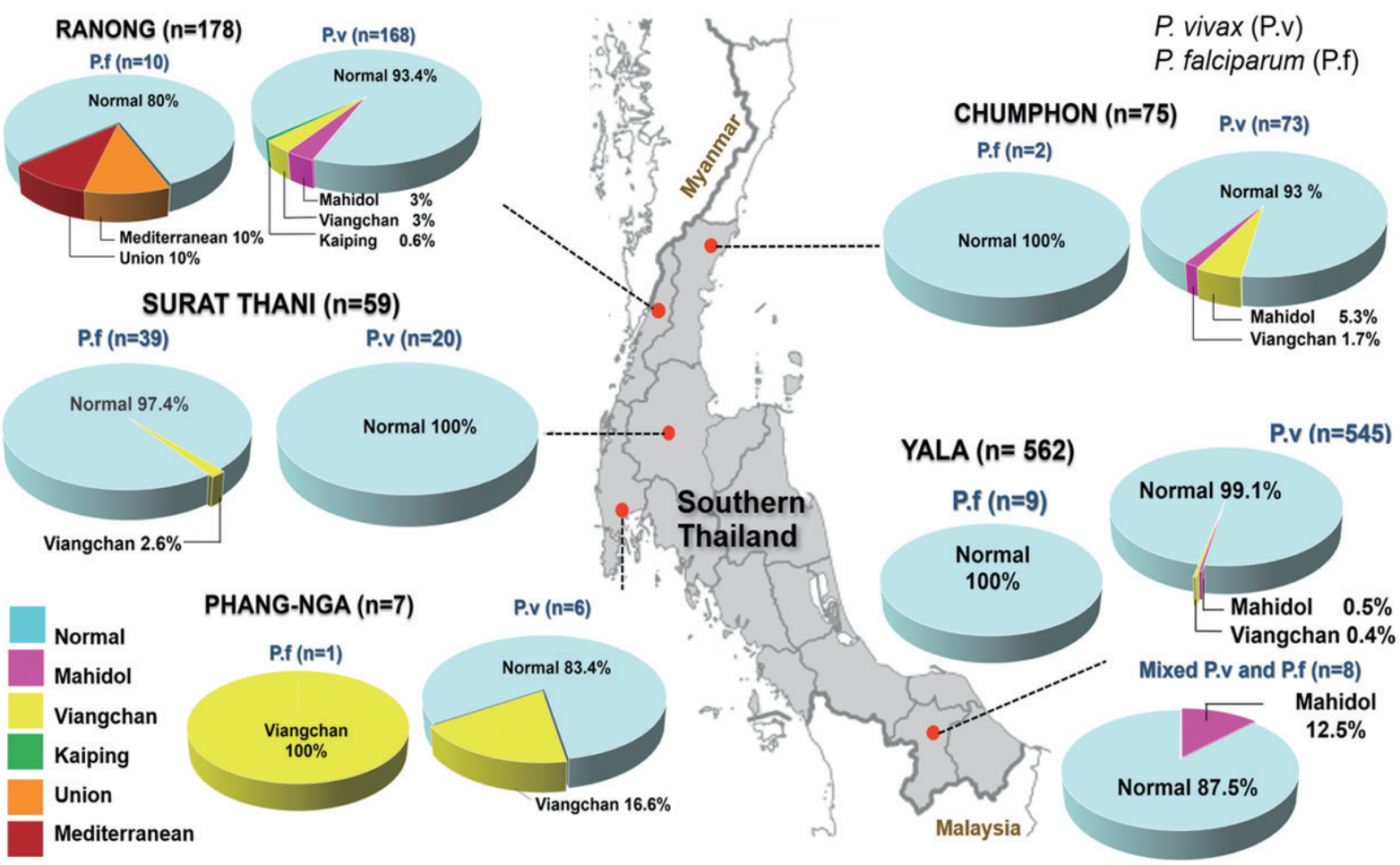

Fig. 1. Geographic distribution of G6PD deficiency variants among malaria-infected individuals in the 5 provinces of southern Thailand.

Table 1. Frequency of G6PD deficiency in southern Thailand

\begin{tabular}{|c|c|c|c|}
\hline & Normal (\%) & G6PD variants (\%) & Total (\%) \\
\hline \multicolumn{4}{|l|}{ Plasmodium parasites } \\
\hline P. vivax & 764 (97.3) & $21(2.7)$ & $785(89.1)$ \\
\hline P. falciparum & $57(93.4)$ & $4(6.5)$ & $61(6.9)$ \\
\hline P. knowlesi & $27(100)$ & 0 & $27(3.1)$ \\
\hline Mixed $P$. vivax and $P$. falciparum & $7(87.5)$ & $1(12.5)$ & $8(0.9)$ \\
\hline \multicolumn{4}{|l|}{ Mutations } \\
\hline Mahidol $(487 G>A)$ & - & $12(46.2)$ & $12(1.4)$ \\
\hline Viangchan $(871 \mathrm{G}>\mathrm{A})$ & - & $11(42.4)$ & $11(1.3)$ \\
\hline Kaiping $(1388 \mathrm{G}>\mathrm{A})$ & - & $1(3.8)$ & $1(0.1)$ \\
\hline Union $(1360 \mathrm{C}>\mathrm{T})$ & - & $1(3.8)$ & $1(0.1)$ \\
\hline Mediterrenean $(563 \mathrm{C}>\mathrm{T})$ & - & $1(3.8)$ & $1(0.1)$ \\
\hline \multicolumn{4}{|l|}{ Gender } \\
\hline Male & $492(97.2)$ & $14(2.8)$ & $506(57.4)$ \\
\hline Female & $287(96)$ & $12(4)$ & $298(33.9)$ \\
\hline No data & $77(100)$ & - & $77(8.7)$ \\
\hline \multicolumn{4}{|l|}{ Ethnics } \\
\hline Thai & 760 (97.6) & $19(2.4)$ & $779(88.4)$ \\
\hline Burmese & 93 (93.9) & $6(6.1)$ & 99 (11.2) \\
\hline Laos & $2(66.7)$ & $1(33.3)$ & $3(0.4)$ \\
\hline \multicolumn{4}{|l|}{ Locations } \\
\hline Ranong & 165 (92.6) & $13(7.4)$ & $178(20.2)$ \\
\hline Chumphon & $71(94.7)$ & $4(5.3)$ & 75 (8.5) \\
\hline Phang-nga & $5(71.4)$ & 2 (28.6) & $7(0.8)$ \\
\hline Surat Thani & 58 (98.2) & $1(1.8)$ & $59(6.7)$ \\
\hline Yala & 556 (98.9) & $6(1.1)$ & $562(63.8)$ \\
\hline Total number & 855 (97.1) & $26(2.9)$ & $881(100)$ \\
\hline
\end{tabular}




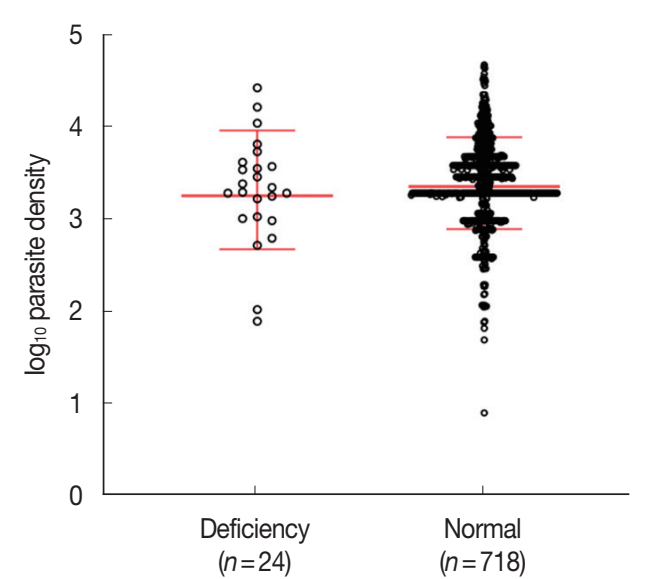

Fig. 2. Comparison of parasitemia between patients with G6PD deficiency and normal.

in the lower part. Mahidol and Viangchan variants were the highest distribution in the upper south regions.

\section{Associations between G6PD deficiency and parasitemia}

Parasite densities were compared among the G6PD-deficient $(n=24)$ and G6PD-normal $(n=718)$ samples. The average of parasite densities of G6PD-deficient and G6PD-normal samples were 4,456 (80-28,118 parasites/ $\mu \mathrm{ll})$ and 4,141 (8-47,607 parasites $/ \mu \mathrm{l})$, respectively. There was no significant difference in parasitemia between G6PD-deficient and G6PD-normal groups (two-tailed unpaired t-test, $P=0.539 ;$ Fig. 2). Fig. 3 describes the relationship between parasitemia and each of the variants of G6PD deficiency. The patients bearing the commonest variants, Viangchan and Mahidol, presented 2,738

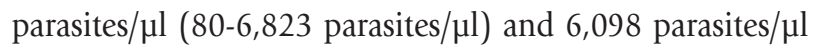
(538-28,118 parasites/ $\mu$ ) in the blood. The parasitemia of the 3 individuals with Kaiping, Union, and Mediterranean variants was 3,701, 107, and 11,551 parasites/ $\mu l$, respectively. In addition, the data showed that the mean of parasitemia of G6PD-deficient individuals infected with $P$. vivax was higher than that of $P$. falciparum infection, 4,717 parasites/ $\mu$ l (538-

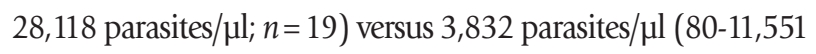
parasites $/ \mu \mathrm{l} ; n=4)$, respectively.

\section{DISCUSSION}

The present retrospective cohort study investigates the prevalence of G6PD variants in malaria patients isolated from southern Thailand. The performance of G6PD screening before malaria treatment is uncommon in Thailand, which could impose

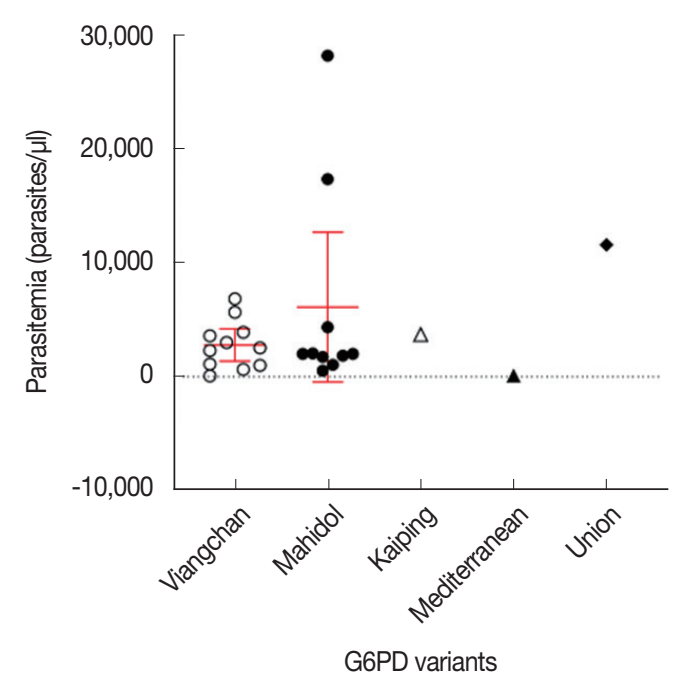

Fig. 3. Analysis of parasitemia among patients carrying the different G6PD variants.

the patients at risk of hemolysis. G6PD deficient populations were relatively more common in the upper provinces of southern Thailand than in the southernmost region. In Yala province where there were a higher number of malaria cases, the prevalence of the G6PD variant was relatively lower. According to Howes RE et al. [6], approximately $13-17 \%$ of the Thai population carries common G6PD variants. In this study, we analyzed the G6PD genotyping in only the southern region of Thailand. Twenty-six out of 881 malaria samples (2.9\%) were identified as the G6PD mutation variants. The previous study, however, did not find G6PD variants in samples isolated from the southern region due to limited of the samples size, whereas the western, central and north-eastern regions presented G6PD variants in 5.36\%, $14.28 \%$, and $4.76 \%$ respectively [15]. Another study in the southern region revealed that $15.4 \%$ and $15.5 \%$ of healthy Phuket locals of Moken and Thai carried G6PD variants [23]. The lower prevalence of G6PD mutation variants observed in the present study might be due to the limitation of the DiaPlexC G6PD Genotyping Kit (Asian type) which is unable to detect the certain variants such as G6PD Quing Yuan, silent mutation, G6PD Gaohe [19], G6PD Namoru, G6PD Chatham and, G6PD Andalus [31,32].

World Health Organization has classified G6PD variants, based on the level of enzyme activity, into 5 classes from the most severe (Class I) to the mildest (Class IV): Class I, severe deficiency of the enzyme with chronic non-spherocytic hemolytic anemia; Class II severe deficiency with enzyme activity $<10 \%$ of normal; Class III, moderate deficiency with enzyme 
activity $10-60 \%$ of normal; Class IV, very mild to none deficiency with enzyme activity $60-100 \%$ of normal; and Class V, increased enzyme activity [33]. Five types of G6PD mutation variants were identified in this study; Mahidol, Viangchan variants are associated with Class III variants, whereas Kaiping, Union, Mediterranean are associated with Class II variants [34]. However, clinical manifestations are an association between the phenotype and the genotype [35-38]. The low level of G6PD enzyme activity that is presented in G6PD mutations are risk of individuals hematologic changes such as hematocrit drops [39-41].

The Mahidol variant (487G >A) and G6PD Viangchan (871G> A) were the most predominant variants in our study. The previous studies also identified G6PD Mahidol and Viangchan variants as the major variants among healthy individuals in southern Thailand $[17,18]$. These variants were also commonly present in neighboring countries, including Cambodia, Laos, Myanmar [23,42]. We detected a small portion of G6PD Kaiping $(1,388 \mathrm{G}>\mathrm{A})$, Union $(1,360 \mathrm{C}>\mathrm{T})$, and Mediterranean $(563 \mathrm{C}>\mathrm{T})$. Kaiping and Union variants were detected in the Burmese population. Kaiping variants were the most prevalent among the Chinese population in Southern China [43] and Malaysia [44]. It was also found at high frequency among Thai people of southern Thailand [30]. G6PD Mediterranean was commonly predominant in west Asia [5].

Our present study also showed that there was no difference in parasitemia between the G6PD-deficient and G6PD-normal patients. This was in agreement with the previous reports $[20,45]$, which also suggested the absence of significant association between G6PD deficiency and parasite densities. P. vivax is preferentially infecting young red blood cells or reticulocytes, and hence, malaria parasites can replicate within these cells with the normal G6PD enzyme level [46]. A recent study has revealed that parasites produced their own G6PD enzyme to survive within the host red cell [47]. The other report suggests that the parasitized G6PD-deficient erythrocytes were susceptible to phagocytosis by monocytes, which could protect against malaria [48]. Although malaria cases in Thailand have significantly declined, the southern part of Thailand is still facing a high risk of malaria. The region shares 2 borders, with Malaysia in the south and Myanmar in the west, and the greater risk was related to high population mobility along the Myanmar-Thai border and social unrest in provinces bordering with Malaysia [13]. In recent years, P. vivax malaria cases have increased from $72 \%$ in 2016 to $83 \%$ in 2019, even though
P. falciparum showed a reduction in patients [49]. P. vivax parasites are the main species causing severe illness and are relapsing. PQ with the daily dose of $0.25 \mathrm{mg} / \mathrm{kg}$ in 14-day regimen is prescribed to eliminate the dormant hypnozoites [11]. Prescribing PQ without G6PD testing has been reported to cause hemolysis in P. vivax infected patients, particularly at risk for the individuals with low G6PD enzyme activity. Even with the correct dose, intravascular hemolysis in male with G6PD Mahidol variant can occur [50]. It has been demonstrated that the G6PD Viangchan and Mahidol, the most common variants observed in southern Thailand, cause low enzymatic activity in RBCs and risk for acute hemolysis induced by PQ [51,52].

In this study, all dried blood samples were collected from malaria patients attending the malaria clinics. Before giving with Primaquine, the testing for G6PD deficiency is not available according to the national policy for malaria treatment. Hence, the measurement of G6PD enzyme activities is not generally considered at that time. In addition, the methods to determine the G6PD enzyme activity, such as spectrophotometry assay, cytochemical staining assay, fluorescent spot test, and point-of-care G6PD testing, are complex to perform in a field study. Hence, the lack of quantitative measurement of G6PD enzyme activity is a limitation of this study. However, the close relationship between G6PD variants and G6PD phenotypes has been established [35-38]. Further study is required to investigate the level of the G6PD enzyme activity associated with malaria-infected subjects. Therefore, our study highlights the importance of G6PD testing before PQ treatment to prevent hemolysis, raising awareness among healthcare policymakers and supporting the Thailand malaria elimination program.

\section{ACKNOWLEDGMENT}

Funding for this study was provided by a grant from Prince of Songkla University, contract no. MET6302044S and PSUPh.D. Scholarship contract no. PSU_PHD2562-004.

\section{CONFLICT OF INTEREST}

The authors declare that they have no conflict of interest.

\section{REFERENCES}

1. Luzzatto L, Nannelli C, Notaro R. Glucose-6-phosphate dehy- 
drogenase deficiency. Hematol Oncol Clin North Am 2016; 30: 373-393. https://doi.org/10.1016/j.hoc.2015.11.006

2. Gómez-Manzo S, Marcial-Quino J, Ortega-Cuellar D, SerranoPosada H, González-Valdez A, Vanoye-Carlo A, HernándezOchoa B, Sierra-Palacios E, Castillo-Villanueva A, Reyes-Vivas H. Functional and biochemical analysis of glucose-6-phosphate dehydrogenase (G6PD) variants: elucidating the molecular basis of G6PD deficiency. Catalysts 2017; 7: 135. https://doi.org/10.3390/ catal7050135

3. Cappellini MD, Fiorelli G. Glucose-6-phosphate dehydrogenase deficiency. Lancet 2008; 371: 64-74. https://doi.org/10.1016/ S0140-6736(08)60073-2

4. Frank JE. Diagnosis and management of G6PD deficiency. Am Fam Physician 2005; 72: 1277-1282.

5. Howes RE, Dewi M, Piel FB, Monteiro WM, Battle KE, Messina JP, Sakuntabhai A, Satyagraha AW, Williams TN, Baird JK, Hay SI. Spatial distribution of G6PD deficiency variants across malaria-endemic regions. Malar J 2013; 12: 418. https://doi.org/10.1186/14752875-12-418

6. Howes RE, Piel FB, Patil AP, Nyangiri OA, Gething PW, Dewi M, Hogg MM, Battle KE, Padilla CD, Baird JK, Hay SI. G6PD deficiency prevalence and estimates of affected populations in malaria endemic countries: a geostatistical model-based map. PLoS Med 2012; 9: e1001339. https://doi.org/10.1371/journal.pmed.1001339

7. Pathak V, Colah R, Ghosh K. Effect of inherited red cell defects on growth of Plasmodium falciparum: An in vitro study. Indian J Med Res 2018; 147: 102-109. https://doi.org/10.4103/ijmr.IJMR_1146_16

8. Cappadoro M, Giribaldi G, O'Brien E, Turrini F, Mannu F, Ulliers D, Simula G, Luzzatto L, Arese P. Early phagocytosis of glucose6-phosphate dehydrogenase (G6PD)-deficient erythrocytes parasitized by Plasmodium falciparum may explain malaria protection in G6PD deficiency. Blood 1998; 92: 2527-2534. https://doi. org/10.1182/blood.V92.7.2527

9. Guindo A, Fairhurst RM, Doumbo OK, Wellems TE, Diallo DA. X-linked G6PD deficiency protects hemizygous males but not heterozygous females against severe malaria. PLoS Med 2007; 4: e66. https://doi.org/10.1371/journal.pmed.0040066

10. Uyoga S, Ndila CM, Macharia AW, Nyutu G, Shah S, Peshu N, Clarke GM, Kwiatkowski DP, Rockett KA, Williams TN. Glucose6-phosphate dehydrogenase deficiency and the risk of malaria and other diseases in children in Kenya: a case-control and a cohort study. Lancet Haematol 2015; 2: 437-444. https:/doi.org/10.1016/ S2352-3026(15)00152-0

11. Recht J, Ashley EA, White NJ. Use of primaquine and glucose6-phosphate dehydrogenase deficiency testing: divergent policies and practices in malaria endemic countries. PLoS Negl Trop Dis 2018; 12: e0006230. https://doi.org/10.1371/journal.pntd.0006230

12. World Health Organization. Testing for G6PD deficiency for safe use of primaquine in radical cure of $P$. vivax and P. ovale: Policy brief. Geneva, Switzerland. World Health Organization. 2016. https://apps.who.int/iris/handle/10665/250297

13. USAID. President's Malaria Initiative: Thailand, Lao PDR and Regional Abbreviated Malaria Operation Plan FY 2019 [Inter- net]. United States Agency for International Development; [cited 2022 Jan 22]. Available from: https://d1u4sg1s9ptc4z.cloudfront.net/uploads/2021/03/fy-2019-thailand-abbreviated-malaria-operational-plan.pdf

14. Price RN, von Seidlein L, Valecha N, Nosten F, Baird JK, White NJ. Global extent of chloroquine-resistant Plasmodium vivax: a systematic review and meta-analysis. Lancet Infect Dis 2014; 14 : 982-991. https://doi.org/10.1016/S1473-3099(14)70855-2.

15. Nkhoma ET, Poole C, Vannappagari V, Hall SA, Beutler E. The global prevalence of glucose-6-phosphate dehydrogenase deficiency: a systematic review and meta-analysis. Blood Cells Mol Dis 2009; 42: 267-278. https://doi.org/10.1016/j.bcmd.2008.12. 005

16. Boonyuen U, Songdej D, Tanyaratsrisakul S, Phuanukoonnon $\mathrm{S}$, Chamchoy K, Praoparotai A, Pakparnich P, Sudsumrit S, Edwards T, Williams CT, Byrne RL, Adams ER, Imwong M. Glucose6-phosphate dehydrogenase mutations in malaria endemic area of Thailand by multiplexed high-resolution melting curve analysis. Malar J 2021; 20: 194. https://doi.org/10.1186/s12936-02103731-0

17. Charoenkwan P, Tantiprabha W, Sirichotiyakul S, Phusua A, Sanguansermsri T. Prevalence and molecular characterization of glucose-6-phosphate dehydrogenase deficiency in northern Thailand. Southeast Asian J Trop Med Public Health 2014; 45: 187-193.

18. Jitueakul S, Buncherd H, Thawornpan P, Tun AW, Thanapongpichat S. Characterization of G6PD genotypes in G6PD deficiency patients from Suratthani Hospital, Thailand. JAMS 2018; 51: 6671.

19. Ninokata A, Kimura R, Samakkarn U, Settheetham-Ishida W, Ishida T. Coexistence of five G6PD variants indicates ethnic complexity of Phuket islanders, Southern Thailand. J Hum Genet 2006; 51: 424-428. https://doi.org/10.1007/s10038-006-0380-y

20. Laosombat V, Sattayasevana B, Janejindamai W, Viprakasit V, Shirakawa T, Nishiyama K, Matsuo M. Molecular heterogeneity of glucose-6-phosphate dehydrogenase (G6PD) variants in the south of Thailand and identification of a novel variant (G6PD Songklanagarind). Blood Cells Mol Dis 2005; 34: 191-196. https://doi. org/10.1016/j.bcmd.2004.11.001

21. Bancone G, Chu CS, Somsakchaicharoen R, Chowwiwat N, Parker DM, Charunwatthana P, White NJ, Nosten FH. Characterization of G6PD genotypes and phenotypes on the northwestern Thailand-Myanmar border. PLoS One. 2014; 9: e116063. https://doi.org/10.1371/journal.pone.0116063

22. Kanchanavithayakul A, Prasittisa K, Kiat-Amornrak P, Chanda M, Kittiwatanasarn P, Nuchprayoon I, Cheepsunthorn CL. Prevalence of glucose 6-phosphate dehydrogenase deficiency and genetic mutations among karen and lao populations in thailand. Southeast Asian J Trop Med Public Health 2017; 48: 1308-1317.

23. Sathupak S, Leecharoenkiat K, Kampuansai J. Prevalence and molecular characterization of glucose-6-phosphate dehydrogenase deficiency in the Lue ethnic group of northern Thailand. Sci Rep 2021; 11: 2956. https://doi.org/10.1038/s41598-021-82477-w 
24. Phompradit P, Kuesap J, Chaijaroenkul W, Rueangweerayut R, Hongkaew Y, Yamnuan R, Na-Bangchang K. Prevalence and distribution of glucose-6-phosphate dehydrogenase (G6PD) variants in Thai and Burmese populations in malaria endemic areas of Thailand. Malar J 2011; 10: 368. https://doi.org/10.1186/14752875-10-368

25. Bonito B, Polrat Wilairatana P, Tangpukdee N, Muangnoicharoen S, Poovorawan K, Srivicha Krudsood S. Prevalence of glucose6-phosphate dehydrogenase deficiency among vivax malaria patients at the Hospital for Tropical Diseases, Thailand. Southeast Asian J Trop Med Public Health 2019; 50: 211-216.

26. Khammanee T, Sawangjaroen N, Buncherd H, Tun AW, Thanapongpichat S. A LAMP-SNP assay detecting C580Y mutation in Pfkelch13 gene from clinically dried blood spot samples. Korean J Parasitol 2021; 59: 15-22. https://doi.org/10.3347/kjp.2021.59. 1.15

27. Khammanee T, Sawangjaroen N, Buncherd H, Tun AW, Thanapongpichat S. Molecular surveillance of Pfkelch13 and Pfmdr1 mutations in Plasmodium falciparum isolates from Southern Thailand. Korean J Parasitol 2019; 57: 369-377. https://doi.org/10. 3347/kjp.2019.57.4.369

28. Thanapongpichat S, Khammanee T, Sawangjaroen N, Buncherd $\mathrm{H}$, Tun AW. Genetic diversity of Plasmodium vivax in clinical isolates from Southern Thailand using PvMSP1, PvMSP3 (PvMSP3alpha, PvMSP3beta) genes and eight microsatellite markers. Korean J Parasitol 2019; 57: 469-479. https://doi.org/10.3347/ kjp.2019.57.5.469

29. Schoone GJ, Oskam L, Kroon NC, Schallig HD, Omar SA. Detection and quantification of Plasmodium falciparum in blood samples using quantitative nucleic acid sequence-based amplification. J Clin Microbiol 2000; 38: 4072-5407. https://doi.org/10.1128/ JCM.38.11.4072-4075.2000

30. Snounou G, Viriyakosol S, Jarra W, Thaithong S, Brown KN. Identification of the four human malaria parasite species in field samples by the polymerase chain reaction and detection of a high prevalence of mixed infections. Mol Biochem Parasitol 1993; 58: 283-292. https://doi.org/10.1016/0166-6851(93)90050-8

31. Iwagami M, Nakatsu M, Khattignavong P, Soundala P, Lorphachan L, Keomalaphet S, Xangsayalath P, Kawai S, Hongvanthong B, Brey PT, Kano S. First case of human infection with Plasmodium knowlesi in Laos. PLoS Negl Trop Dis 2018; 12: e0006244. https://doi.org/10.1371/journal.pntd.0006244

32. Ainoon O, Yu YH, Amir Muhriz AL, Boo NY, Cheong SK, Hamidah NH. Glucose-6-phosphate dehydrogenase (G6PD) variants in Malaysian Malays. Hum Mutat 2003; 21: 101. https://doi.org/ 10.1002/humu.9103

33. Yusoff NM, Shirakawa T, Nishiyama K, Ghazali S, Ee CK, Orita A, Abdullah WZ, Isa MN, Van Rostenberghe H, Matsuo M. Molecular heterogeneity of glucose-6-phosphate dehydrogenase deficiency in Malays in Malaysia. Int J Hematol 2002; 76: 149-152. https://doi.org/10.1007/BF02982577

34. World Health Organization. Updating the WHO G6PD classification of variants and the International Classification of Diseas- es, 11th Revision (ICD-11). Malaria Policy Committee Meeting. Background document for Session 7. 2019 October 2-4; Geneva, Switzerland. https://www.who.int/malaria/mpac/mpac-october2019-session7-updating-G6PD-classification.pdf

35. Lee J, Kim TI, Kang JM, Jun H, Lê HG, Thái TL, Sohn WM, Myint MK, Lin K, Kim TS, Na BK. Prevalence of glucose-6-phosphate dehydrogenase (G6PD) deficiency among malaria patients in Upper Myanmar. BMC Infect Dis 2018; 18: 131. https://doi.org/ 10.1186/s12879-018-3031-y

36. World Health Organization. Guide to G6PD Deficiency Rapid Diagnostic Testing to Support P. vivax Radical Cure. World Health Organization. Geneva, Switzerland. 2018. https://apps.who.int/ iris/bitstream/handle/10665/272971/9789241514286-eng.pdf

37. Huang Y, Choi MY, Au SW, Au DM, Lam VM, Engel PC. Purification and detailed study of two clinically different human glucose 6-phosphate dehydrogenase variants, G6PD(Plymouth) and G6PD(Mahidol): Evidence for defective protein folding as the basis of disease. Mol Genet Metab 2008; 93: 44-53. https://doi. org/10.1016/j.ymgme.2007.08.122

38. Gómez-Manzo S, Terrón-Hernández J, De la Mora-De la Mora I, González-Valdez A, Marcial-Quino J, García-Torres I, VanoyeCarlo A, López-Velázquez G, Hernández-Alcántara G, OriaHernández J, Reyes-Vivas H, Enríquez-Flores S. The stability of G6PD is affected by mutations with different clinical phenotypes. Int J Mol Sci 2014; 15: 21179-21201. https://doi.org/10.3390/ ijms151121179

39. Au SW, Gover S, Lam VM, Adams MJ. Human glucose-6-phosphate dehydrogenase: the crystal structure reveals a structural $\mathrm{NADP}(+)$ molecule and provides insights into enzyme deficiency. Structure 2000; 8: 293-303. https://doi.org/10.1016/s09692126(00)00104-0

40. Kaplan JC. Defective molecular variants of glucose-6-phosphate dehydrogenase and methaemoglobin reductase. J Clin Pathol Suppl (R Coll Pathol) 1974; 8: 134-141.

41. Piomelli S, Corash LM, Davenport DD, Miraglia J, Amorosi EL. In vivo lability of glucose-6-phosphate dehydrogenase in GdAand GdMediterranean deficiency. J Clin Invest 1968; 47: 940948. https://doi.org/10.1172/JCI105786

42. Bancone G, Chu CS. G6PD Variants and haemolytic sensitivity to primaquine and other drugs. Front Pharmacol 2021; 12: 638885. https://doi.org/10.3389/fphar.2021.638885

43. Khim N, Benedet C, Kim S, Kheng S, Siv S, Leang R, Lek S, Muth S, Chea N, Chuor CM, Duong S, Kerleguer A, Tor P, Chim P, Canier L, Witkowski B, Taylor WR, Ménard D. G6PD deficiency in Plasmodium falciparum and Plasmodium vivax malaria-infected Cambodian patients. Malar J 2018; 12: 171. https://doi.org/10. 1186/1475-2875-12-171

44. Jiang W, Yu G, Liu P, Geng Q, Chen L, Lin Q, Ren X, Ye W, He Y, Guo Y, Duan S, Wen J, Li H, Qi Y, Jiang C, Zheng Y, Liu C, Si E, Zhang Q, Tian Q, Du C. Structure and function of glucose6-phosphate dehydrogenase-deficient variants in Chinese population. Hum Genet 2006; 119: 463-478. https://doi.org/10.1007/ s00439-005-0126-5 
45. Wang J, Luo E, Hirai M, Arai M, Abdul-Manan E, Mohamed-Isa Z, Hidayah N, Matsuoka H. Nine different glucose-6-phosphate dehydrogenase (G6PD) variants in a Malaysian population with Malay, Chinese, Indian and Orang Asli (aboriginal Malaysian) backgrounds. Acta Med Okayama 2008; 62: 327-332. https://doi. org/10.18926/AMO/30966

46. Lo E, Zhong D, Raya B, Pestana K, Koepfli C, Lee MC, Yewhalaw D, Yan G. Prevalence and distribution of G6PD deficiency: implication for the use of primaquine in malaria treatment in Ethiopia. Malar J 2019; 18: 340. https://doi.org/10.1186/s12936-019-2981-x

47. Kitcharoen S, Dechyotin S, Khemtonglang N, Kleesuk C. Relationship among glucose-6-phosphate dehydrogenase (G-6-PD) activity, G-6-PD variants and reticulocytosis in neonates of northeast Thailand. Clin Chim Acta 2015; 442: 125-129. https:// doi.org/10.1016/j.cca.2015.01.017

48. López C, Saravia C, Gomez A, Hoebeke J, Patarroyo MA. Mechanisms of genetically-based resistance to malaria. Gene 2010467 : 1-12. https://doi.org/10.1016/j.gene.2010.07.008

49. Ayi K, Turrini F, Piga A, Arese P. Enhanced phagocytosis of ringparasitized mutant erythrocytes: a common mechanism that may explain protection against falciparum malaria in sickle trait and beta-thalassemia trait. Blood 2004; 104: 3364-3371. https:// doi.org/10.1182/blood-2003-11-3820

50. Udom C, Thanispong K, Manguin S, Chareonviriyaphap T, Fungfuang W. Trophic Behavior and species diversity of the Anopheles barbirostris Complex (Diptera: Culicidae) in Thailand. J Med Entomol 2021; 58: 2376-2384. https://doi.org/10.1093/jme/tjab067

51. Chu CS, Bancone G, Soe NL, Carrara VI, Gornsawun G, Nosten F. The impact of using primaquine without prior G6PD testing: a case series describing the obstacles to the medical management of haemolysis. Wellcome Open Res 2019; 4: 25. https://doi.org/ 10.12688/wellcomeopenres.15100.2

52. Rueangweerayut R, Bancone G, Harrell EJ, Beelen AP, Kongpatanakul S, Möhrle JJ, Rousell V, Mohamed K, Qureshi A, Narayan S, Yubon N, Miller A, Nosten FH, Luzzatto L, Duparc S, Kleim JP, Green JA. Hemolytic potential of tafenoquine in female volunteers heterozygous for glucose-6-phosphate dehydrogenase (G6PD) deficiency (G6PD Mahidol Variant) versus G6PD-normal volunteers. Am J Trop Med Hyg 2017; 97: 702-711. https://doi. org/10.4269/ajtmh.16-0779

53. Chu CS, Bancone G, Nosten F, White NJ, Luzzatto L. Primaquineinduced haemolysis in females heterozygous for G6PD deficiency. Malar J 2018; 17: 101. https://doi.org/10.1186/s12936-018-2248-y 
